\title{
UK leukaemia study implicates nuclear reprocessing plants
}

\section{London}

A NUCLEAR reprocessing complex at Dounreay, in Scotland, is the most likely cause of an increased incidence of leukaemia among young people living in the vicinity, a government-commissioned study has concluded. The independent Committee on Medical Aspects of Radiation in the Environment, chaired by Professor Martin Bobrow, head of paediatric research at Guy's Medical School in London, found that six cases of childhood leukaemia were registered in the area between 1979 and 1984, when only one would have been expected. The precise reason for the anomaly remains elusive, however, and the committee was unable to attribute the increased leukaemia incidence to the low levels of radioactive discharge from the site.

Increased incidences of leukaemia among children have also been found around Britain's only other nuclear reprocessing plant, at Sellafield, in Cumbria. The committee's report concludes: "The evidence of a raised incidence of leukae-

\section{Problems over TPA patent for Genentech in Japan}

\section{Tokyo}

GENENTECH's worldwide battle to defend its patents covering the clot-dissolving glycoprotein called tissue plasmogen activator (TPA) suffered another setback at the end of last month, when the company failed to win a temporary injunction to halt clinical trials by a Japanese competitor, Toyobo.

But part of Genentech's problems in Japan seems to be a judge who does not understand genetic engineering. Meanwhile, Toyobo is nearing completion of its clinical trials. The patent dispute is the first in Japan involving recombinant DNA technology; it is a revealing illustration of the differences between US and Japanese patent law.

Genentech's patent was announced by the Japanese patent office in April last year, when several companies immediately filed objections. Under Japanese law, the patent will become effective only if and when these claims are cleared - a process that is expected to take about another year. Although, in the United States, patents remain confidential until granted, Japanese patent law provides opportunities for public review and opposition before patents are registered.

As in the case of the fight against Genentech's patent in the British courts by the UK company Wellcome, Genentech's competitors are objecting to the very broad nature of the US company's Japanese patent. In Japan, patents are typically very narrowly defined, and this in part accounts for the huge numbers of patents filed by Japanese companies.

Meanwhile, several Japanese companies are racing to put recombinant TPA on the market as a drug for heart attacks. Mitsubishi Chemical and Kyowa Hakko have licensing agreements with Genentech, while Sumitomo Pharmaceutical has an agreement with Wellcome.
Toyobo, which has licensed technology from the US company Integrated Genetics, is thought to be Genentech's closest rival in Japan. In August last year, Genentech filed a suit in the Osaka local district court alleging patent infringement by Toyobo, and demanding a ban on Toyobo's production, marketing and sales promotion of recombinant TPA as well as on the conduct of clinical trials.

Japanese trials of such patent disputes are notoriously prolonged; Genentech's case is expected to take at least two or three years. That is why, in February, Genentech also filed for a temporary injunction to halt Toyobo's clinical trials, pending a decision in its case. Although applications for such injunctions are usually decided fairly rapidly, the judge ruled in April that the injunction should be discussed alongside the case of patent infringement.

Now a further delay has been imposed. A new judge has been assigned to the case and, despite a mound of documents submitted by Genentech and Toyobo, said at the latest hearing on 31 May (according to a report in Nikkei Biotechnology) that "The court does not yet understand the real point of contention. The detailed documents . . . are difficult to read. If possible the plaintiff and defendant should point out the problematical points". The next hearing is on 28 July.

Genentech brought in Nobel prizewinner Paul Berg to help explain its case in the April hearing. The company has also approached some Japanese academics for help, but they are generally reluctant to become involved in court hearings.

Meanwhile, Toyobo is in phase two of the clinical trials and may be able to apply to the Ministry of Health and Welfare for marketing approval before a decision on the temporary injunction is reached.

David Swinbanks mia near Dounreay, taken in conjunction with that relating to the area around Sellafield, tends to support the hypothesis that some feature of the nuclear plants that we have examined leads to an increased risk of leukaemia in young people living in the vicinity of those plants."

The Dounreay site, acquired by the UK Atomic Energy Authority (UKAEA) in 1955, has operated three nuclear reactors and their associated fuel fabrication and reprocessing plants and is Britain's centre for fast reactor development.

The study examined leukaemia incidence between 1968 and 1984 in an area within $25 \mathrm{~km}$ of the nuclear complex. During that time six cases were registered among people aged $0-24$, twice the number expected on the basis of national rates, but a figure that was nevertheless statistically insignificant. However, five of the cases occurred within a distance of $12.5 \mathrm{~km}$ from the site, a threefold excess. Most strikingly, all six cases within the full $25-\mathrm{km}$ zone were registered in the last sixyears of the study period, a 12-fold increase on national rates and an observation the committee describes as "remarkable".

On the question of possible causes, the committee says that on present estimates, risk to the fetus and infants arising from discharge at the Dounreay site would not account for the increased incidence of leukaemia. It notes, however, that data concerning leukaemia risk following lowlevel radiation exposure in utero and in infancy are "limited". Furthermore, limited knowledge about the physical and chemical forms of radionuclides concerned, their distribution in the body and the relevant target tissue for leukaemogenesis, particularly for children, means that it remains a possibility that some feature of the discharges could generate much higher doses to the target organs than present estimates would suggest. One common feature of Dounreay and Sellafield is that actinides, which emit radiation with a high linear-energy transfer, are discharged from both sites in a much higher proportion that from nuclear power generating plants.

The committee has recommended investigation into a number of alternative possibilities, including unrecognized pathways of radionuclide transfer in the environment, and possible pre-conception effects of low-level radiation.

The UKAEA commended the report for its "high quality", but predictably emphasized that the study was not conclusive. The authority's chairman, $\mathrm{Mr}$ John Collier, pledged support for future studies but was keen to point out that "leukaemia clusters were identified long before the nuclear age and exist in countries with no nuclear plants, like New Zealand". 